\title{
Public Policy-Making in the Perspective of Emergency Management
}

\author{
Hui-Dan YUE
}

\author{
Humanities and Law School of Northwestern Polytechnic University, Changan Campus, \\ $\mathrm{Xi}$ ' an, Shaanxi province, China \\ Email:yuehuidan@163.com
}

Keywords: Emergency ,Public Policy-making, Trigger action, Optimization.

\begin{abstract}
The emergencies frequently take place with the gradual deepening of the social transformation in China. Such emergencies and a series of reactions triggered by them have become a common condition in the public policy-making. In the policy practice to respond to the emergencies, the emergency-oriented public policy-making to deal with emergencies as the primary goal, has broken the routine and quickly enacted relevant policies, and we have achieved the effect of "turning crisis into machine". However, this kind of policy making with obvious emergent tendency inevitably, and has many quality defects. In order to give full play to the positive effect, it must be improved and optimized. And our ultimate goal is to get out of the deep crisis that our society is facing.

With the gradual deepening of the social transformation in china, the frequent occurrence of emergencies has become normalized. While bringing unavoidable negative effects, the frequent occurrence of emergencies and a series of reactions caused by them has played an objective triggering role in the public policy-making. In the perspective of the frequent occurrence of emergencies, how to further deepen the research and strengthen the exploration, so as to we can grasp the objective policy triggering mechanism of emergencies timely, and utilize it effectively. In fact, it is not only an important theoretical problem, but also an important practical problem. It is very helpful for us to respond to emergencies properly, and provide useful implication for the government to improve their capacity of emergency management. Practice has proved that all of these played an increasing greater significance role, for solving the urgent social problems, promoting the innovation of public policy, and enhancing the Government's credibility.
\end{abstract}

\section{Emergency and Public Policy}

In the western countries, emergency is often defined by the concept of crisis. Correspondingly, emergency response is also called crisis management. In china, in terms of its connotation, the most authoritative summary is the definition in emergency response law of the people's republic of china. It clearly states that: emergencies refer to events that occur, cause or may cause serious social harm and need to take emergency measures to deal with, including natural disasters, accidents disasters, public health incidents and social security events. ${ }^{[1]}$ It is an indisputable fact that all kinds of emergencies occurrence frequently, in the modern risk society. In china, the special background of social transformation determines that the frequent occurrence of emergencies is closely related to the imperfection of existing institutional policies. In essence, emergency is the manifestation of the potential social contradictions and social problems that was accumulated and intensified ${ }^{[2]}$. The emergency has the basic characteristics, such as the sudden outbreak, the uncertain development, the harmful consequences, the urgent situation, the attentive public opinion, the objective opportunity, and so on. It is just these characteristics that make the occurrence of emergency and a series of reactions caused by it has broken the normal and habitual path of public policy-making in a way. At the same time, it objectively putted forward a opportunity to solve the social problem, and opened a policy window, which has formed the special opportunity for the public policy's formulation and improvement in a certain sense.

Public policy is a public management activity of the public authority, which aiming at the social public question, for the purpose of balance and coordinate the social public interest. It can be seen that the formulation and implementation of public policy is oriented by social problems and public 
value. The government's function or the policy's value lies in its timely and effective for solving social problems and resolving social contradictions. However, because of the problem of concept or cognition, and the limitation of resources or ability, not all major social problems can be foreseen and recognized by the government, and then enter the policy agenda. There are some issues that are ignored and covered up, then put on the edge, not be responded effectively in the long run. Which resulting in the insufficiency of effective public policy supply, and even severe lag. On the one hand, more and more serious social contradictions have not been coordinated, on the other hand, new social problems are emerging in endlessly and have not been solved in time. Eventually, social contradictions and social problems have intensified, and manifested in the form of an emergency, the social problems and policy flaws behind them have been fully exposed. The fact has showed that, the incompetence of public policy has become an important reason for the emergency's breaking out. Emergency management must optimize and improve the public policy.

It can be seen that public policy is closely related to emergency, which interact and influence each other. Therefore, public policy should be an appropriate part of emergency management, and the emergency should be a necessary angle for public policy-making.

\section{The Interaction between Emergency Management and Public Policy -Making}

Emergency: trigger mechanism of public policy- making.

The trigger mechanism for policy making was first proposed by John w. kinden, a prominent American public policy scientist. He believed that many of the general social issues are on the policy agenda, and become the policy issues that the government is addressing, contingency events play an important role in it.[3] Then, in the book public policy-making :process and principles[4], Raleigh- N. Geston has made a further systematic analysis of the trigger mechanism of policy making. He named the power that led to public problems into the government's agenda and became a policy issue as a trigger mechanism. Influenced by the urgency and focus of the emergency, an ordinary daily problem is rapidly transformed into a common, negative and strong public reaction, and then promoted the establishment of the policy agenda with the power of public opinion. Which providing a special opportunity and condition for policy making, the promulgation or change of the public policies emerged due to these opportunities. Thus, emergency can serve as an important trigger mechanism for public policy-making.

In china, the government's public policy-making practice has been continuously improved in order to deal with the challenge of the emergencies. In this process of the emergency-oriented public policy-making, the unique triggering function of emergency has been gradually manifested. In recent years, there have been many cases of innovation related policies due to the trigger mechanism of emergency. For instance, the sars in early 2003, which promoted the rushing out of public health emergency regulation. The sun zhi-gang event in march 2003, which triggered the rapid change form methods to resettlement and repatriation the homeless and the beggars to methods to aid and manage the homeless and the beggars in the urban areas. The birth of management regulation for school bus safety, which is stemmed from the major school bus accident in 2011. These are all representative and typical cases in the practice of policy making that emergency-oriented.

The trigger action of emergency on public policy is objective existence, and its unique function is the result of the combination of the emergency and a series of logical effects caused by it. It includes: emergency's convex mirror effect, which exposing the policy shortcomings, clearing policy issues. Aggregation public opinion effects, which leading to the policy needs, promoting the pressure to make policy. Rethinking opportunity effects, which triggering the improvement of policy and optimizing the policy. As the trigger mechanism of the public policy-making, all this effects respectively play the roles in stimulating the public policy-making.

Policy making: the core of emergency management.

As the public affairs manager, the representative of the public interest, fully respond to various emergencies, has been the government's legal duty since ancient times. Any government, no matter what type of government it is, will not be allowed emergencies to unfetter. In fact, it will take some 
emergency measures to provide social assistance, in order to effectively maintain the normal order of the society, that just is the essential part of government's public management. The government's response is the central factor of the emergency management, which is based on the government's own responsibility and resources, and also the comparable advantages of government over other response actors. Emergency management is a complex work, it involves the specific coping strategies and measures are multifaceted, through the formulation and implementation of public policy to response is an important step. When the emergency itself is caused by the delay or error of the policy, and pointed at the policy-flaw, the government's policy response becomes an inevitable choice. It turned out, the core of public crisis management lies in the policy-making in crisis situation.[5]This is jointly determined by the particularity of emergency and its special response, and the intrinsic characteristics of public policy.

The urgency, uncertainty and destructiveness of the public crisis determine the concentration, rapidity and efficiency of crisis decision-making, and the authority, compulsion and flexibility of public policy accord with the response needs of public crisis, so as to effectively regulate and guide the behaviors of all stakeholders.[6]It can be seen that public policy, as the basic form of government's public management, is also the main tool for the government to deal with emergency. Modern risk society, with the frequent occurrence of emergencies, actively coping with emergencies has become a prominent feature of modern public policy. After the emergencies, the government consciously enhance the diagnostic capabilities, adjust the policy-making agenda, improve the policy-making strategies and finally realize the improvement of the public policy-making. As for the emergency management in the normal situation, the continuous optimization and improvement of public policy will help to prevent emergencies occurring frequently from the source, to nip the emergencies in the bud as far as possibly. It’s the best strategy for emergency management.

\section{Policy Making in Emergency Response}

\section{Policy Dilemmas in Emergency.}

Looking around the world, with the development of the times, public crisis has become more and more widespread, and has caused the general adversity of public policy-making. As an important tool for solving social problems, public policy is very dependent on social environment. So for china, which is in a high-risk period of social transformation, the problems of public policy itself are outstanding. The complexity of China's social transformation and the special form of the emergencies caused by that, which determines that the special situation generated by the frequent occurrence of the emergencies bring the dilemmas to the public policy-making are also significant. Public policy itself is a complicated game of interest, the interest factor is the fundamental reason that obstructs the reform of public policy. Policy innovation will inevitably meet the resistance of vested interests, and it is a difficult process to seek policy innovation.

Despite in the emergency situation, the public's intense concern can quickly reach a consensus on certain policy issues, and reduce the resistance of policy innovation to some extent. However, the uncertainty of development in emergency and its powerful harmfulness have put forward more serious challenges to policy making, urgently need the government's functional departments and their staffs to make a special response which is different from the normal one. The unconventional decision-making puts higher requirements on the psychology and creativity of decision-makers. And asks about the public policy system itself has a strong self-criticism and self-improvement ability, which can be extremely difficult in emergency. In particular, the policy dilemmas in the emergency are mainly included:[7]the complexity of policy issues' identification, the unconventional nature of the policy-making process, the limitation of available resources, the risk of policy decision-making. And the dilemmas of policy-making reflected in the limited time, the arduous execution-task, the scarce execution-resources, the poor execution -environment, etc. Facing these dilemmas, the policy making inevitably have obvious emergency tendency. It is easy to cause the quality defects of the public policy, such as the short-term phenomenon, the idealization-behavior, the operational not strong, and so on. 
However, when a certain event burst and caused an emergency situation, the core values and fundamental interests of the social system are seriously threatened, the government must respond quickly to minimize the loss caused by the emergency. Regardless of the completeness of decision-making conditions, the adequacy of policy costs, the optimization of emergency policy. Therefore, although there may be many difficulties and drawbacks in the policy making in emergency, its unique triggering effect on policy making is exist objectively. Which has become an important policy-making model for turning Crisis into machine.

\section{Policy Optimization in Emergency Response.}

In the risk society, all kinds of emergencies occurred frequently, which has provided a realistic rationality for taking the opportunity of emergencies to formulate and optimize the public policies. If the government can break the routine, break through the dilemma, seize the objective policy-opportunity provided by the emergency timely and effective, and turn the protruding problems exposed by emergency, the new requirements arising from emergency, the experience and lessons learned from the improper disposal and policy mistakes of emergency respond, into the new impetus to make and optimize the related policy, thus revise and improve it pertinently. In this way, we can effectively promote the optimization and perfection of public policy in china. It should be noted that such emergency-oriented public policy-making, is still adhering to a passive emergency thinking.[8]In the long run, if the government always follow such a path to develop policies, it is easy for the public policy-making practice to fall into a inefficient path dependence, and lacking of consistency, integrity and foresight Whether from the current policy practice in our country, or the future policy development, the public policy-making mode to respond to emergency should be optimized.

Under the frequent occurrence of emergencies, to re-examine the public policy of our country. What we need to do is to think about and reconstruct the concept of public management, improve the policy ability and quality of relevant departments and their staffs. To promote the reconstruction and reform of the basic institution, remove the constraints of the macro-institutional framework that restrict china's policy capacity, and to solve social problems fundamentally. To establish and improve emergency management system, explore the coping strategies of emergencies further, improve the standardization and effectiveness of system operation. To build a policy platform of transition-strategy, strengthen the construction of law, and to promote the democratization and scientific of policy making. To strengthen the supervision of public opinion, cultivate the citizen's policy participation consciousness and ability, and so on.

Above all, under the frequent occurrence of emergencies, we should take advantage of the objective opportunity provided by trigger mechanism of emergencies, to accelerate the public policy-making, optimize and change the existing public policy, and to promote the public policy keeping pace with the times. That is a realistic choice to us. But more importantly, we should take such opportunity to confront the deep crisis of emergency management and public policy, strengthen the construction of policy capacity in risk social, which is a fundamental path for Chinese government to strengthen and consolidate its legitimacy foundation.

\section{References}

[1]Emergency Response Law of the People's Republic of China, China Legal press, Beijing, 2007:3.

[2]Xue Lan, Zhang Qiang, Zhong Kai-bin. Crisis Management, tsinghua university press, Beijing, 2003:8.

[3]John w. kinden, Agenda, Alternatives and Public Policy, second ed, Ding huang, Fang xing(Translators), Renmin university of China press, Beijing, 2004:257.

[4]Geston, Larry.N, Public Policy-Making: Process and Principles, Macmillan, New York, 1997.

[5]Li Ming-qiang, Liu Hong-tao, The problems and Countermeasures of Public Policy in Public 
Crisis Management in China: Thoughts on Basis of the May 12 WenChuan Earthquake, J. Changjiang Forum. 2008(6):50.

[6]Qian Zheng-rong, Research on Public Crisis Governance under the View of Policy Competence, Wuhan University Press, Hubei, 2014:137.

[7]Yang fang, The Value and Dilemma of Public Policy in the State of Crisis, J. Academia, 2011(3):38-40.

[8]Han li-li, Research on the Emergency-oriented Social Policy-making Mode in China, Social sciences press, Beijing, 2010:181. 